\title{
Investigation of Hypergolic Fuels with Hydrogen Peroxide
}

\author{
Brian M. Melof and Mark C. Grubelich \\ Explosive Projects and Diagnostics, Dept. 2554 \\ Sandia National Laboratories \\ P.O. Box 5800 \\ Albuquerque, New Mexico, 87185-1454
}

\begin{abstract}
A low toxicity, high performance, hypergolic, bipropellant system is desired to replace conventional nitrogen tetroxide (NTO) and hydrazine propulsion systems. High-test hydrogen peroxide exothermically decomposes to water, and oxygen, making it an ideal oxidizer for more environmentally friendly propulsion systems. Unfortunately, the choice of fuel for such systems is not as clear. Many factors such as ignition delay, performance, toxicity, storability, and cost must be considered. Numerous candidate fuels and fuel/catalyst mixtures were screened using a simple laboratory setup and visual observation. A mixture of ethanolamine and $1 \%$ copper II chloride was found to rapidly ignite with $90 \%$ hydrogen peroxide. Hydrogen peroxide and ethanolamine are much less toxic than NTO and hydrazine. Peroxide and ethanolamine have a calculated specific impulse of 245 seconds compared to 284 seconds for NTO and monomethyl hydrazine.
\end{abstract}

\section{Introduction}

Many applications such as attitude control thrusters, divert propulsion engines, and small rocket systems require storable, hypergolic, liquid propellants having good performance. Nitrogen tetroxide (NTO) and hydrazine is the traditional propellant combination used for such applications. There are many advantages to this propellant pair such as rapid ignition, good performance, low freezing point, and storability. There are also distinct disadvantages to this propellant combination. NTO has a high vapor pressure and is very corrosive to both rocket hardware and the human body. Hydrazines are reactive, corrosive, and very toxic. ${ }^{1}$ Most hydrazine compounds are carcinogenic. ${ }^{1}$

A search is underway for less toxic, hypergolic, liquid propellants that can be used is new propulsion systems and in systems currently using NTO and hydrazine. Concentrated hydrogen peroxide is an ideal oxidizer for such applications due to its lower toxicity, high density, low vapor pressure, and exothermic decomposition to water and oxygen. The challenge is to find a low toxicity fuel that gives rapid hypergolic ignition with hydrogen peroxide, as well as exhibiting good performance, safety, and storability.

Our quest for a non-toxic hypergol began by researching the literature. Most current publications utilized alcohols as their fuels of choice. ${ }^{2,3,4}$ Alcohols are cheap, storable, have low freezing points, exhibit good performance, and are non-toxic compared to hydrazines. ${ }^{1}$ Unfortunately,

Sandia is a multiprogram laboratory operated by Sandia Corporation, a Lockheed Martin Company, for the United States Department of Energy under Contract DE-AC04-94AL85000. 


\section{DISCLAIMER}

This report was prepared as an account of work sponsored by an agency of the United States Government. Neither the United States Government nor any agency thereof, nor any of their employees, make any warranty, express or implied, or assumes any legal liability or responsibility for the accuracy, completeness, or usefuiness of any information, apparatus, product, or process disciosed, or represents that its use would not infringe privately owned rights. Reference herein to any specific commercial product, process, or service by trade name, trademark, manufacturer, or otherwise does not necessarily constitute or imply its endorsement, recommendation, or favoring by the United States Government or any agency thereof. The views and opinions of authors expressed herein do not necessarily state or reflect those of the United States Government or any agency thereof. 


\section{DISCLAIMER}

Portions of this document may be illegible in electronic image products. Images are produced from the best available original document. 
hypergolic ignition was only achieved after adding a large amount ( $>10 \%)$ of manganese based catalyst. ${ }^{2,3,4}$ Metallic catalysts are toxic and impair performance, so low concentrations are desired. In addition, an insoluble catalyst may not remain in uniform suspension and convert a hypergolic fuel into one with inconsistent age related performance. We wanted to find a fuel that was hypergolic by itself or that could be made so with a much smaller addition of metallic catalyst.

\section{Background}

Hydrogen peroxide serves as an oxidizing agent in the combustion of organic fuels. The driving force behind these reactions is the conversion of oxygen in the -1 oxidation state to oxygen in the -2 oxidation state. Fuels that are strong reducing agents should facilitate this conversion and thus be very reactive with hydrogen peroxide. Furthermore, hydrogen peroxide is weakly acidic having a pKa of $11.65 .^{5}$ Under basic conditions, peroxide loses a proton and becomes much less stable. ${ }^{6}$ In addition to being good reducing agents, potential fuels should also be basic if possible.

The above conclusions were reinforced by Schumb in his ACS monograph on peroxide. ${ }^{7}$ Schumb describes several classes of organic compounds that are reportedly hypergolic with hydrogen peroxide. Among those mentioned were inorganic amines, some organic amines, diammines, unsaturated compounds, aldehydes, and compounds containing hydroxy groups. All the fuels mentioned by Schumb have electron rich areas on the molecule that can act as reductants with hydrogen peroxide, and the amino compounds are also basic.

Schumb adds that the effect may be markedly increased by the addition of metal salts. Although details of metal catalysis are not known, the net effect of the metal catalyst is the lowering of the activation energy and the promotion of the reaction between fuel and peroxide.

Based on this information, a number of saturated and unsaturated compounds having hydroxy, carbonyl, and amino functionality were obtained. A hydrazine replacement known as DMAZ (2Dimethylamino ethyl azide) was also obtained. Several hydrocarbon fuels that are non-miscible with peroxide were selected in the hope of finding a soluble organometallic catalyst that would make them hypergolic.

Metallic compounds of $\mathrm{Co}^{+2}, \mathrm{Co}^{+3}, \mathrm{Cu}^{+1}, \mathrm{Cu}^{+2}, \mathrm{Fe}^{+2}, \mathrm{Fe}^{+3}, \mathrm{Mn}^{+2}, \mathrm{Mn}^{+3}, \mathrm{Ag}^{+1}, \mathrm{Ru}^{+2}, \mathrm{~V}^{+2}$ and sodium and calcium hypochlorite were tried as fuel catalysts.

\section{Experimental}

A simple laboratory test was developed to screen potential rocket fuels. In these "drop" tests, a $0.1 \mathrm{~mL}$ portion of candidate fuel was placed into a $5 \mathrm{~mL}$ disposable polyethylene cup. Approximately $0.4 \mathrm{~mL}$ of $90 \%$ hydrogen peroxide was added to the fuel using an automatic pipette. A 1" length of silicone rubber tubing was slipped over the tip of the glass pipette and replaced after each test, to prevent contamination and allow re-use of the pipette. Visual observation determined if ignition occurred and the relative rate and intensity of reaction. Figure 1 shows the experimental setup. 


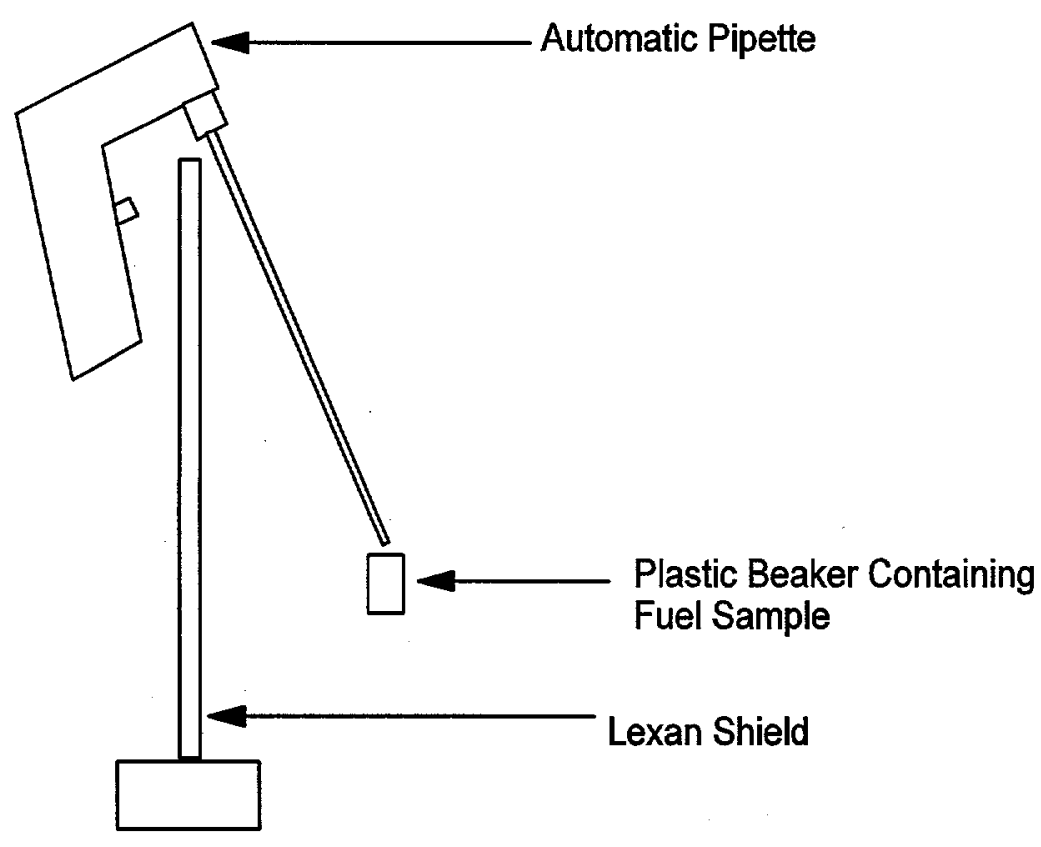

Figure 1: Drop test apparatus.

\section{Results}

Drop test results from $90 \%$ hydrogen peroxide and various catalysts, fuels, and fuel/catalyst mixtures are presented in tables 1-3. Reaction rate and reaction intensity between peroxide and candidate materials was rated on a relative scale from 0 to 2, with 2 being the fastest and most reactive.

Most catalysts gave a vigorous reaction with hydrogen peroxide and those having an organic fraction ignited. Catalyst reactivity was very fast and difficult to rank. Only copper II acetylacetonate failed to react with peroxide. Of the fuels tested, DMAZ, toluidine, diethylenetriamine, ethylenediamine, pyrrole, ethanolamine, and triethyl aluminum/hexane gave noticeable reactions with peroxide. Only pyrrole, ethanolamine, and triethyl aluminum/hexane ignited.

To decrease ignition delay, metal compounds were added to the most reactive fuels. A $1 \%$ mass addition of copper II chloride to pyrrole and ethanolamine gave "instant" ignition on contact with hydrogen peroxide. Other mixtures reacted violently with peroxide, but failed to ignite in the drop tests. A $25 \%$ solution of triethyl aluminum in hexane was the only non-miscible fuel that was hypergolic with peroxide. No catalysts were found that made the other non-miscible fuels hypergolic. 


\section{Discussion}

A wide variety of fuels were tested, but only fuels having amino functionality showed any reaction with peroxide. Almost all catalysts greatly accelerated the decompositon of peroxide although no clear trend was observed. Copper salts are very soluble in amines due to complex formation. For this reason, copper II chloride was added to ethylenediamine, ethanolamine, and pyrrole. It was hoped that the addition of catalyst would greatly accelerate the reaction between fuel and peroxide. One thing not tried was mixing metallic catalysts to obtain a synergistic effect. It is reported that pairs of metal catalysts have a greater effect on the decomposition of hydrogen peroxide than either metal alone. ${ }^{6}$ This will be investigated in future work.

The ethanolamine mix ignited very rapidly upon contact with peroxide. The ethylenediamine complex vigorously steamed, but no combustion occurred. The drop tests are not representative of the intense mixing that takes place as a result of injecting propellants into the combustion chamber of a rocket motor. We expect that many of the reactions that were vigorous in the drop test apparatus will be hypergolic in a rocket motor. The pyrrole complex was rapidly hypergolic, but after a week of storage, a thick sludge formed that eventually solidified. This reinforces the need for long term aging and compatability studies for fuels. DMAZ gave a slight reaction with peroxide, but metal catalysts were not added because the stability of such mixtures was unknown.

Ethanolamine is the best fuel tested due to its high density, low toxicity, respectable performance, and rapid ignition as seen in Tables 4 and 5. It does however have one major drawback, a freezing point of $10.3{ }^{\circ} \mathrm{C} .90 \%$ hydrogen peroxide freezes at $-11.5^{\circ} \mathrm{C}$. A solution to this problem is the addition of a lower freezing point solvent such as ethanol $\left(\mathrm{mp}-114.1^{\circ} \mathrm{C}\right)$, methanol $\left(\mathrm{mp}-97.8{ }^{\circ} \mathrm{C}\right)$, propyl amine $\left(\mathrm{mp}-83^{\circ} \mathrm{C}\right)$, or diethylenetriamine $\left(\mathrm{mp}-35^{\circ} \mathrm{C}\right)$. This will bring the freezing point of the fuel to that of the peroxide, but the concentrations necessary are unknown as is the effect on ignition delay.

Only a brief mention of hypergolic non-miscible fuels was given by Schumb. Hypergolic ignition was achieved by suspending a sizeable percentage of metallic catalyst in the fuel. We wanted to find a soluble catalyst that could be added at low concentrations and still provide hypergolic ignition. There are performance, handling, and cost advantages to using non-miscible fuels such as jet fuel or gasoline. It was theorized that the dicyclopentadienyl complexes of iron, manganese, cobalt, and ruthenium would be soluble in hydrocarbons at a level that would promote hypergolic ignition. Kerosene, trimethyl pentane, and limonene were blended with the aforementioned organo-metallics. One percent additions of catalyst did not promote ignition in any of the compounds. Higher catalyst concentrations created solubility problems with many of the fuel/catalyst combinations.

\section{Conclusions}

A simple test was devised to determine if candidate fuels were hypergolic with $90 \%$ hydrogen peroxide. Metal catalysts, fuels, and fuel/catalyst mixtures were tested and their relative reactivities determined by visual observation.

All catalysts except copper II acetylacetonate reacted quickly and violently with $90 \%$ hydrogen 
peroxide. Manganese, copper, and iron compounds gave the most vigorous reactions followed by silver, cobalt, ruthenium, and vanadium compounds. DMAZ, diethylenetriamine, ethylenediamine, pyrrole, and ethanolamine, reacted with peroxide. The only fuels that ignited were pyrrole, ethanolamine, and triethylaluminum/hexane. A 1\% addition of copper II chloride to pyrrole and ethanolamine gave rapidly hypergolic mixtures with $90 \%$ peroxide. Upon storage, the pyrrole and copper II chloride mixture polymerized, leaving catlayzed ethanolamine as the only practical hypergolic fuel. Ethanolamine copper chloride mixtures have a low toxicity, high density, favorable performance, and short ignition delay. The main disadvantages are the high viscosity and high freezing point of the mixture. Addition of alcohol or other amines should eliminate these problems without increasing ignition delay. A $25 \%$ solution of triethyl aluminum in hexane was the only hypergolic non-miscible fuel mixture found.

Future work includes small rocket engine test firing of all potential fuels and determining the minimum peroxide concentration and minimum catalyst concentration necessary for hypergolic ignition. The effect of mixed catalysts on ignition delay will be studied and further attempts will be made at making non-miscible fuels hypergolic with hydrogen peroxide.

\section{References}

1. Lewis, Richard J. Sr. Hazardous Chemicals Desk Reference, $4^{\text {th }}$ ed. New York: John Wiley \& Sons, 1997.

2. Funk, J. E., Rusek, J. "Assessment of United States Navy Block 0 NHMF/RGHP Propellants", Proceedings: Second International Hydrogen Peroxide Propulsion Conference, 1999, November.

3. Meade, C. J., Lormand, B. M., Purcell, N. L. "Status of Non-Toxic Hypergolic Miscible Fuel Development at NAWCWD China Lake", Proceedings: Second International Hydrogen Peroxide Propulsion Conference, 1999, November.

4. Austin, B. L. Jr., Frolik, S., Porras, G., Etheridge, L. J., Rusek, J. J. "Characterization of Non-Toxic Hypergolic Bi-Propellants", Proceedings: Second International Hydrogen Peroxide Propulsion Conference, 1999, November.

5. Greenwood, N. N., Earnshaw, A. Chemistry of the Elements. $2^{\text {nd }}$ ed. Oxford: Butterworth-Heinemann, 1997.

6. Kirchner, J. R. "Hydrogen Peroxide", Kirk-Othmer Encyclopedia of Chemical Technology, $4^{\text {th }}$ ed. New York: John Wiley \& Sons, 1995.

7. Schumb, Walter C., Satterfield, Charles N., Wentworth, Ralph L. Hydrogen Peroxide. New York: Reinhold, 1955. 
Table 1. Catalyst drop test results.

\begin{tabular}{|l|c|l|}
\hline CATALYST & DELAY & COMMENTS \\
\hline Cobalt II Acetyl Acetonate & 3 & Ignition \\
\hline Cobalt III Acetyl Acetonate & 2 & $\begin{array}{l}\text { Decomposed then ignited after } \\
\text { several seconds }\end{array}$ \\
\hline Dicyclopentadienyl Cobalt II & 3 & Ignition \\
\hline Copper I Chloride & 3 & Violent decomposition \\
\hline Copper II Chloride & 3 & Violent decomposition \\
\hline Copper II Acetyl Acetonate & 0 & No Reaction \\
\hline Iron II Chloride & 3 & Violent decomposition \\
\hline Iron III Chloride & 3 & Violent decomposition \\
\hline Iron III Ethoxide & 3 & Violent decomposition \\
\hline Dicyclopentadienyl Iron II & 2 & Decomposed and burned \\
& 3 vigorously after several seconds \\
\hline Manganese II Methoxide & 3 & Ignition \\
\hline Manganese II AcetyI Acetonate & 3 & Ignition \\
\hline Manganese III AcetyI Acetonate & 3 & Ignition \\
\hline DicyclopentadienyI Manganese II & 3 & Ignition \\
\hline Dicyclopentadienyl Ruthenium II & 3 & Ignition \\
\hline Silver I Permanganate & 2 & Rapid decomposition \\
\hline Silver I Acetyl Acetonate & 1 & $\begin{array}{l}\text { Decomposed then ignited after } \\
\text { several seconds }\end{array}$ \\
\hline Vanadium II Acetyl Acetonate & Ignition \\
\hline Sodium Hypochlorite & Steady decomposition \\
\hline Calcium Hypochlorite & 3 & Steady decomposition \\
\hline
\end{tabular}

Delay

$0=$ No Reaction

$1=$ Slow Reaction

2= Fast Reaction

$3=$ Very Fast Reaction 
Table 2. Fuel drop test results.

\begin{tabular}{|c|c|c|c|}
\hline FUEL & DELAY & $\begin{array}{l}\text { IGNITION } \\
\text { POTENTIAL }\end{array}$ & COMMENTS \\
\hline Methanol & 0 & 0 & No Reaction \\
\hline Ethanol & 0 & 0 & No Reaction \\
\hline Ethylene Glycol & 0 & 0 & No Reaction \\
\hline Furfuryl Alcohol & 0 & 0 & No Reaction \\
\hline$\alpha-$ Terpineol & 0 & 0 & No Reaction \\
\hline Furaldehyde & 0 & 0 & No Reaction \\
\hline Ethylenediamine & 2 & 1 & Rapidly decomposed \\
\hline Dietylenetriamine & 2 & 1 & Rapidly decomposed \\
\hline Triethyl Amine & 0 & 0 & No Reaction \\
\hline Furfuryl Amine & 0 & 0 & No Reaction \\
\hline Toluidine & 1 & 1 & Decomposed \\
\hline Pyrrole & 2 & 2 & Delayed ignition \\
\hline Ethanolamine & 2 & 2 & Delayed ignition \\
\hline Phenyl Hydrazine & 0 & 0 & No Reaction \\
\hline $\begin{array}{l}\text { 2-Dimethylaminoethyl azide } \\
\text { DMAZ }\end{array}$ & 1 & 1 & Slow decompostion \\
\hline Kerosene & 0 & 0 & No Reaction \\
\hline Trimethyl Pentane & 0 & 0 & No Reaction \\
\hline Limonene & 0 & 0 & No Reaction \\
\hline $\begin{array}{l}25 \% \text { Triethyl Aluminum in } \\
\text { Hexane }\end{array}$ & 3 & 3 & Ignition \\
\hline Red Phosphorous & 3 & 3 & Ignition \\
\hline Decaborane & 0 & 0 & No Reaction \\
\hline
\end{tabular}

Delay

$0=$ No Reaction

$1=$ Slow Reaction

$2=$ Fast Reaction

$3=$ Very Fast Reaction
Ignition Potential

$0=$ No Potential for Ignition

$1=$ Slight Ignition Potential

$2=$ High Ignition Potential

$3=$ Very High Ignition Potential 
Table 3. Fuel mixture drop test results.

\begin{tabular}{|c|c|c|c|}
\hline MIXTURE & DELAY & $\begin{array}{l}\text { IGNITION } \\
\text { POTENTIAL }\end{array}$ & COMMENTS \\
\hline $\begin{array}{l}\text { Ethanolamine } \\
\text { Copper II Chloride }\end{array}$ & 3 & 3 & $\begin{array}{l}\text { Instantly ignited with a green } \\
\text { flame }\end{array}$ \\
\hline $\begin{array}{l}\text { Pyrrole } \\
\text { Copper II Chloride }\end{array}$ & 3 & 3 & $\begin{array}{l}\text { Instantly ignited, but solidified } \\
\text { during storage }\end{array}$ \\
\hline $\begin{array}{l}\text { Ethylenediamine } \\
\text { Copper II Chloride }\end{array}$ & 2 & 2 & $\begin{array}{l}\text { Violent steam evolution, but no } \\
\text { flame }\end{array}$ \\
\hline $\begin{array}{l}\text { Ethanol } \\
\text { Manganese II Acetyl Acetonate }\end{array}$ & 2 & 1 & $\begin{array}{l}\text { Vigorous steam evolution, but no } \\
\text { flame }\end{array}$ \\
\hline $\begin{array}{l}\text { Ethanol } \\
\text { Ruthenium Chloride }\end{array}$ & 1 & 1 & Moderate steam evolution \\
\hline $\begin{array}{l}\text { Kerosene } \\
\text { Dicyclopentadienyl Iron II }\end{array}$ & 0 & 0 & Slight fizzing after many minutes \\
\hline $\begin{array}{l}\text { Kerosene } \\
\text { Dicyclopentadienyl Manganese II }\end{array}$ & 0 & 0 & Slight fizzing after many minutes \\
\hline $\begin{array}{l}\text { Kerosene } \\
\text { Dicyclopentadienyl Cobalt II }\end{array}$ & 0 & 0 & Slight fizzing after many minutes \\
\hline $\begin{array}{l}\text { Kerosene } \\
\text { Dicyclopentadienyl Ruthenium II }\end{array}$ & 0 & 0 & Slight fizzing after many minutes \\
\hline $\begin{array}{l}\text { Trimethyl Pentane } \\
\text { Dicyclopentadieny| Iron II }\end{array}$ & 0 & 0 & Slight fizzing after many minutes \\
\hline $\begin{array}{l}\text { Trimethyl Pentane } \\
\text { Dicyclopentadienyl Manganese II }\end{array}$ & 0 & 0 & Slight fizzing after many minutes \\
\hline $\begin{array}{l}\text { Trimethyl Pentane } \\
\text { Dicyclopentadienyl Cobalt II }\end{array}$ & 0 & 0 & Slight fizzing after many minutes \\
\hline $\begin{array}{l}\text { Trimethyl Pentane } \\
\text { Dicyclopentadienyl Ruthenium II }\end{array}$ & 0 & 0 & Slight fizzing after many minutes \\
\hline $\begin{array}{l}\text { Limonene } \\
\text { Dicyclopentadienyl Iron II }\end{array}$ & 0 & 0 & Slight fizzing after many minutes \\
\hline $\begin{array}{l}\text { Limonene } \\
\text { Dicyclopentadienyl Manganese II }\end{array}$ & 0 & 0 & Slight fizzing after many minutes \\
\hline $\begin{array}{l}\text { Limonene } \\
\text { Dicyclopentadienyl Cobalt II }\end{array}$ & 0 & 0 & Slight fizzing after many minutes \\
\hline $\begin{array}{l}\text { Limonene } \\
\text { Dicyclopentadienyl Ruthenium II }\end{array}$ & 0 & 0 & Slight fizzing after many minutes \\
\hline
\end{tabular}

All mixtures were $99 \%$ fuel and $1 \%$ catalyst by weight. 
Table 4: Propellant performance calculated by NEWPEP.

\begin{tabular}{|ll|l|l|}
\hline & PROPELLANT & \multicolumn{1}{|c|}{ ISP } & $\begin{array}{c}\text { DENSITY } \\
\text { ISP }\end{array}$ \\
\hline $\begin{array}{l}71.4 \% \\
28.6\end{array}$ & $\begin{array}{l}\text { Nitrogen Tetroxide } \\
\text { Monomethyl Hydrazine }\end{array}$ & 287 & 345 \\
\hline $\begin{array}{l}70.3 \% \\
29.7\end{array}$ & $\begin{array}{l}\text { Hydrogen Peroxide (90\%) } \\
\text { Hydrazine }\end{array}$ & 275 & 343 \\
\hline $\begin{array}{l}83.1 \% \\
16.9\end{array}$ & $\begin{array}{l}\text { Hydrogen Peroxide (90\%) } \\
\text { Ethanol }\end{array}$ & 261 & 321 \\
\hline $\begin{array}{l}90.1 \% \\
9.9\end{array}$ & $\begin{array}{l}\text { Hydrogen Peroxide (90\%) } \\
\text { JP-4 }\end{array}$ & 259 & 327 \\
\hline $\begin{array}{l}80.1 \% \\
19.9\end{array}$ & Hydrogen Peroxide (90\%) & 245 & 316 \\
\hline
\end{tabular}

Table 5: Physical properties of ethanolamine.

\begin{tabular}{|l|l|}
\hline Molecular Weight, g/mol & 61.08 \\
\hline Density, g/mL & 1.012 \\
\hline Freezing Point, ${ }^{\circ} \mathrm{C}$ & 10.3 \\
\hline Boiling Point, ${ }^{\circ} \mathrm{C}$ & 170.8 \\
\hline Flash Point ${ }^{\circ} \mathrm{C}$ & 90.6 \\
\hline Viscosity, cP & 19 \\
\hline pKa & 9.4 \\
\hline
\end{tabular}

